\title{
Widening the Scope and Scale of Sustainability Assessments in Built Environments: From Passive House to Active Neighbourhood
}

Spela Verovsek

University of Ljubljana, Faculty of Architecture, Zoisova 12, Ljubljana, Slovenia,

Matevz Juvancic

University of Ljubljana, Faculty of Architecture, Zoisova 12, Ljubljana, Slovenia

Tadeja Zupancic

University of Ljubljana, Faculty of Architecture, Zoisova 12, Ljubljana, Slovenia

Doi: 10.2478/ajis-2018-0013

\begin{abstract}
The paper provide an insight into the research conducted by the University of Ljubljana, and the Urban institute of Slovenia committed to the assessment of the efficiency related to the management of local resources at the level of neighbourhoods. The reduction of energy consumption and energy efficient built environments are key objectives of many sustainability agendas which is followed by suitable assessment methods in urban analytics. However, there are two important hesitations occurring: first, traditional assessment methods that focus solely on the energy reduction and efficiency are often too narrow in their analysis and limited in their scope of impact. According to the recent advances in research worldwide, efforts solely related to reduction of energy consumption will unlikely lead to more responsive environments or rise the living quality. Thus, more comprehensive methodologies for assessing and monitoring the change and transformation in built environments shall be sought for to reach long-term sustainability. Second, to date, the majority of the evaluation methods - whether focusing to energy consumption or broader sustainability issues - are building- or household- oriented, thus systematically examining separate spatial and social entities, but neglecting the spaces between, the holistic aspect and the community aspect. The research develops structured evaluation model, where two main research pillars are addressed: 1) the development of the structured and modular system of indicators; and 2) the development of the methodology to interpret the resulting values. The paper presents first two stages of the research process and subjects the outcomes to the debate.
\end{abstract}

Keywords: sustainability, community, assessment, renewal, neighborhood.

\section{Introduction}

The outcomes of the recent studies point out the need for a radical shift towards acquiring wider picture for a long-term sustainability and responsiveness of the built environments (Lombardi and Trossero, 2013; Clark et al., 2013), accordingly also he needs for the development of the suitable assessment tools for monitoring the progress of such settings are brought forth. To date, the majority of the evaluation methods - whether focusing to energy consumption or broader 
sustainability issues - are building- or household-oriented, thus systematically examining separate spatial and social entities, but neglecting the spaces between (connecting infrastructure and services, mobility, public space and urban design solutions etc.), the holistic aspect and the community aspect. The methodology for energy impact assessment at the level of individual buildings has already been developed, enacted and implemented in European and Slovenian frames; therefore solid foundations are set to bring this practice onto the subsequent levels following the agenda from achieving passive houses, net-zero houses and similar, towards achieving more efficient neighbourhoods ${ }^{1}$, more active and engaged communities and more associated concerns about the common local resources. This brings public spaces and the neighbourhood communities firmly into the focus.

In this paper we provide an insight into the research committed to the assessment of the efficiency related to the management of local resources at the level of existent Slovenia neighbourhoods. The research proposes consistent and clearly defined targeted criteria, which makes the goals of the sustainable policies more tangible and is at the same time fundamental, meaningful notions both for the residents as well as for the planners and contractors in sustainable neighbourhood retrofitting/renewal. Specifically, the research develops structured evaluation model, i.e., neighbourhood sustainability assessment framework ${ }^{2}$, based on the modular system of indicators and to it connected methodology for the interpretation of resulting values. The designed instrument pinpoints potential weaknesses and low performance segments on the basis of quantitative and qualitative parameters of sustainable efficiency and determines the necessity for appropriate actions.

The reason for addressing the issue at hand is a distinguished lack of instruments to collect and assess overall efficiency and rational use of resources in the existing settlements and their parts (districts, neighbourhoods) in a consistent and comparable way through a unique frame of key criteria and indicators, which provide foundation for targeted interventions. Another aspect is the particularity ${ }^{3}$ of the Slovenian build environments, based on the historic developments and past policies and tendencies to the renewal instead of new design, all together requiring adoption of the existing evaluation methods.

\section{From Passive House to Active Neighbourhood}

In line with recognizing the importance of neighborhoods as the frontlines in the battle for sustainability (Choguill, 2008) the focus has been in parallel turned also to the development of the assessment frameworks for these scales. The methodology for impact assessment has been first developed and implemented at the level of individual buildings through nowadays well recognized certification standards and tools ${ }^{4}$. These tools are commonly applied to planned constructions and hypothetically consider the whole lifespan of it (from planning and construction to use, maintenance renewal and final deconstruction). With the continuing expansion of urbanized areas the basic

\footnotetext{
${ }^{1}$ As claimed by Waldron and Miller (2013) neighbourhood refers to a sub-set of an urban contexture that contains, and is connected by, people, public and private spaces, buildings, and infrastructure and that supports various functions (e.g., living, working, playing, learning and other functions). Neighbourhoods are therefore defined both in spatial or population terms contextualizing a socio-cultural dimensions, as well as a sense of belonging and place attachment.

${ }^{2}$ A neighborhood sustainability assessment tools are instruments that evaluate the sustainability performance of a given neighborhood against a set of criteria and corresponding indicators (Sharifi and Murayama, 2013).

${ }^{3}$ Due to past socio-cultural and political-economic situation, Slovenia's housing stock has a specific structure (heterogeneity) which is reflected in neighborhoods. The leaps in building scale, height, type and density are a frequent and common trait in Slovenia's neighborhoods. In this regard we are not focusing only on residential neighborhoods of larger cities but we also take in neighborhoods of smaller towns, villages and even complete hamlets that show the specifics of common Slovene neighborhoods.

${ }^{4}$ Such as BREEAM (Building Research Establishment's Environmental Assessment Method), DGNB (Deutsche Gesellschaft für Nachhaltiges Bauen), CASBEE (Comprehensive Assessment System for Building Environment Efficiency), LEED (Leadership in Energy and Environment Design) etc.
} 
operating component of strategic planning and research has moved towards the scale of a neighbourhood or a local community, providing a manageable and at the same time diverse unit with the ability to contribute a lion's share to attaining sustainability objectives and the quality living objectives at the city level. There is a growing evidence and recognition that cities shape up through numerous socio-economic and policy-shaping transactions at the district- or neighbourhood- like scales (Waldron and Miller, 2013). Scaling up results in complex interactions and the assessments of the sustainability performance are proving to be much more than the summation of individual buildings and infrastructures (Haapio, 2012; Mori and Christodoulou, 2012). And further, the interactions ad relations that are covered by larger scales may significantly alter the results which may have been valid on the building scale (Bourdic et al., 2012).

Therefore, the measure of the neighbourhood foresees better opportunities to observe, analyse or evaluate urban design practices, community patterns as well as peoples' engagement. It is also recognized as a favourable point to build a sustainable community (Sharifi and Murayama, 2013). This suggests that communities of people engaged in the conceptualization, design, development and on-going life of buildings, neighbourhoods and districts hold considerable potential for contributing to urban sustainability and higher proportions of responsiveness. Another pragmatic point is that at these scales a major part of public spaces and infrastructures are captured and, strategically taken, are directly managed by local or state institutions and thus measures are not limited to the stimulation of individuals but can represent completely realizable modules of actions for improving efficiency and rational management of all kinds of local resources.

\section{Methodologies}

\subsection{Inventory}

A comprehensive review and an inventory of existing methodologies for the assessment of the built environments were conducted using the Scopus and WOS search engines in 2016. 87 papers were extracted and processed due to two or more of the relevant searching parameters - neighbourhood assessment, assessment tool, renewal, sustainability/principles, and efficiency of the resources. After the first analysis that had validated the true relevance of the papers, we decided to eliminate 38 papers not adequately linked or relevant to our objectives. A considerable number of eliminated studies have focused on solely building performance assessment or were narrowly focusing to specific aspects of sustainability such as energy efficiency assessment or waste and water management assessment. These papers were reviewed separately to better understand the specific areas but were not included in the analyses. Additionally we revised two international standards: ISO 37120:2014 Sustainable development of communities - Indicators for city services and quality of life and ISO/TS 37151:2015 Smart community infrastructures - Principles and requirements for performance metrics.

As a result we identified a collection of papers and tools from a wide array of sources. Commercial and non-commercial tools were taken into the consideration. The aim was to cover the tools that most frequently appear in the literature and, as far as possible, cover the variety of the broad field that can be viewed as sustainability assessment.

The review has revealed range of frameworks for neighbourhood sustainability assessment developed across the world in last decades, among which the most widely recognized are systems such as LEED-ND (Leadership in Energy and Environment Design - Neighborhood Development), BREEAM - Communities (Building Research Establishment's Environmental Assessment Method Communities), CASBEE-UD (Comprehensive Assessment System for Building Environment Efficiency - Urban Development), HOE2R (HQE High Quality Environmental standard) etc. Specific attention was dedicated to the papers providing meta-analyses done in this field. Several authors have investigated the categories and criteria in the above mentioned tools through their comparison (e.g. Haapio, 2012; Berardi, 2013; Sharifi and Murayama 2015; Lin and Shih, 2016) to discuss the current situation. Majority of the meta-analyses take three to seven most popular tools into the comparison. 


\subsection{Framework setup}

There were series of the revisionary expert panels organized and applied from December 2016 to June 2017 to progress this framework in terms of relevant criteria and indicators. This first expert group was multidisciplinary (architect, geographer, civil engineer, economist) covering different proficiencies and expertize (energy performance certification of buildings - evaluator, net-zero and passive houses expert, urban risk management, public participation etc.). Special concern at the panels was committed to formerly less inspected levels of "in-between" spaces and infrastructures (which is actually a main point of a neighbourhood scale).

After the reflective inquiry and insight into the problematics of the existing neighbourhoodscaled assessment frameworks, combined with the results of the revisionary expert panels we set a structure of criteria and indicators within the frames of five main assessment categories:

- energy efficiency

- environmental efficiency

- efficient use and management of the built environment

- residents' and communities' engagement level

- exploitation of ICT smart technologies by the citizens

Each category was set on the three strategic levels:

- individual building/household

- $\quad$ public space/in-between spaces/public infrastructure

- mobility infrastructure/mobility organisation

In terms of theoretically considered sustainability coverage, this allowed us to address most of the pragmatic features that conduct the sustainable/unsustainable practices in the neighbourhoods.

As a result a multi-criteria framework was established. The main principle of such framework encompasses the hierarchical and modular system of categories, criteria and sub-levelled indicators/metrics. Each category was defined by a set of criteria (and sub-criteria) and the corresponding indicators which being quantitative or qualitative measures. At this stage we decided to equally weight the criteria, however after the testing of the framework, we will estimate the necessities for weighing/pondering particular indicators or criteria.

The framework proposes three main types of data sourcing:

- official existing datasets (descriptive and cartographic) and calculations,

- expert estimation,

- survey-based sourcing (residents, community).

After the first empirical survey and the response of the residents, we will estimate the potentials to cover data deficiencies by residents' contribution. Also the techniques of the data crowdsourcing will be further examined.

\subsection{Empirical testing}

To test, validate and complement the first outline of the indicators, we will further prepare a series of empirical examinations and surveys. Six Slovene pilot neighbourhoods are applied to serve as a "research testing ground". The selection of pilot neighbourhoods is based on four key selection criteria that ensure heterogeneity of sample neighbourhoods and thus allow for a greater universality of the final instrument for the Slovene territory. Special concern will be committed to data availability and possible systematizations of the data collecting. Alternative indicators will be pursued in cases where levels of availability are typically low.

\section{Discussion}

Reviewing the literature on assessment tools with regard to the generic core criteria for sustainability underlines the relevance of the different sustainability aspects applied. None of the debated tools/instruments cover the same aspects of the sustainability criteria nor cover them completely comparably. There is of course a logical reason for this. The instruments and tools, evolving from the integrated planning, monitoring and evaluation efforts use multi- or 
interdisciplinary approaches to addressing complex problems of relevance to policy and decisionmaking entities which makes sustainability coverage different or at least structured in a different way. Another reason for the discrepancies lie in the diversity of the geo-spatial and cultural backgrounds and with this related recognition of the relevance, which reflects the diversity of opinions about how to address sustainability at the neighbourhood level. Although the efforts in multi-criteria rating systems have turned from environmental issues (Berardi, 2013) towards others, there is little consensus on what should be covered by social or economic pillar. The least covered aspects that we have examined appear to be related to the human resources and scopes such as the community involvement, engagement of smart technologies, preserving spatial identity etc., there is an evident lack of measurable indicators that could provide with reliable information regarding such topics at such scale. One of the remarks that was also noticed by other authors (e.g. Clark et al., 2013) is that the frameworks fail in providing with less tangible aspects of the assessment, such as 'place liveability', 'atmosphere', 'experienced diversity', or 'sense of identity'. This deficiency could lead to a skewing of coverage away from issues that considerably affect users' and residents' spatial experience and perception of quality living environment which - taken as a consequence - derives from either sustainable/prudent or poor design decisions. Likewise, no framework addresses the problem of unsustainable lifestyles directly, even though personal consumption accounts for $30 \%$ to $45 \%$ of total emissions (Säynäjoki et al., 2012).

The literature review exposed another tendency: although a number of studies have been conducted to evaluate the potential of urban renewal, studies on sustainability assessment in urban renewal at a neighbourhood scale are often neglected (Zheng et al., 2016; Blum and Grant 2006). Possible reason for this inadequacy is the fact, that many of the neighbourhood assessment tools identified are based in earlier building-scale versions and are in fact spin-offs (Sharifi and Murayama, 2013) of the commercial building assessment tools (usually intended for the certification of the new constructions), that covers district level and reach beyond the single building, but following a similar process in identifying performance categories, outlining specific goals and targets for each category. Such tools are commonly applied to new built constructions, considering the whole lifespan of them, however, not specifically accommodated to existing stock nor implemented as solely a diagnostic tool (but a certification tool). Considering the current building trend, $80 \%$ of Slovenian dwelling stock existent in 2050 is already built today, with a majority being constructed and designed under the principles not adequate to what we nowadays consider sustainable. Thus, the biggest share and consequently the greatest opportunity lie in the buildings and neighbourhoods that were not designed according to these principles and would undergo a renewal which represents the highest potential for energy use reduction, emission reduction or other efficiency optimization. As also claimed by Batty (2012), the build environment have limited lifespans and have to be renewed continuously. New growth or absolute decay tends to be a relatively small proportion of the total change, which requires different approach in integrated planning, monitoring as well as evaluating the existing stock. Urban renewal on the neighbourhoods level typically occur on the gradual bases which makes most of the existing assessment tools not adequate due to their focus on the new build projects and facilities.

In the process of selecting the criteria and discussing the indicators feasibility we encountered significant data requirements. The issue of possible data scarcity for the scale of neighbourhood was identified in our very initial stages of work. Literature gives relatively little answers to this question although it seems very crucial for the overall operability of the assessments instruments and actual implementations. Lützkendorfa and Balouktsia (2017) recommend to primarily investigate the available data sources and data before describing additional building structures on how to fulfil these requirements. In analysed applications (e.g. Kreutz, 2009; Bird, 2015; Sullivan and Rydin, 2015) the lack of data for the quantitative evaluation was most commonly fixed by performing qualitative assessment on the bases of trained expert estimation or a wider area was used as a proxy for performance against an indicator or more indicators. However in many elaborated cases the interpretation of results was limited by several identified data gaps and preexisting data-quality issues. Some common suggestions propose (Karol, 2009) that if assessment tools are to become firmly anchored in mainstream statistical data collection systems, it is vital to identify what are the most important measures in a particular locality and a decision needs to be 
made regarding what units of measure are to be used.

Foreseeing the lack of available data at the neighborhood level, our study contemplates special examination (transversal objective) of availability, accessibility, adequacy and usefulness of the existing indicators, and the possibility of unleashing the potential of smart services and networks for sourcing micro-spatial data. Modern technology at disposal provides various possibilities for mass crowdsourcing (»collective sensing « concept), which can represent a valuable source of time-specific and locally-specific data and details, comprising various aspects of our everyday, our habits, views, observations, attitudes and preferences. Fine-grained urban sensing (e.g. via smart phones) coupled with well-established remote sensing mechanisms would greatly enhance our potentials in terms of increased geographical resolution of captured data, denser timescale and finer eloquence. However there are numerous limitations on this way, such as adaption of the established indicators, data privacy issue, personal data protection, reliability of such data, to more technical ones such as the establishment of necessary computer applications, platforms, data storage, transfers etc.

\section{Conclusions}

Many of the past practices that were taken for granted, such as planning cities around automobile transportation, and zoning for single uses, has turned out to be less economically, environmentally, or socially viable than necessary to cope with the nowadays and future challenges. Smart decisions are now to be in the Up-to-date and data-driven decisions can well serve the enhanced abilities to respond and adapt to these challenges in a "smart" manner. Rerecord-keeping and monitoring the progress of neighbourhoods from the diverse aspects of sustainable development, as well as shortterm and long-term comparability of successful retrofitting implementations across neighbourhoods in Slovenia is one of the primarily targeted goals of this research. Our efforts promote the potential for highlighting the frame of manoeuvrable room in urban renewal and design through data-driven support, giving consideration both to users' demands/needs as well as to sensitivity and responsiveness of the mere spatial reality, which in turn influences the users' behaviour as well as reveal the spatial thresholds in terms of social, economic and environmental constraints. By this framework we are addressing traceable and tangible spatial phenomena and elements and their cause-effect connection to everyday experience of dwelling, so the abstract notion of sustainability becomes concrete and publicly accessible. This allows for engaging people more firmly into the process of decision-making as well as provokes public spatial literacy, this is, fostering public ability to recognize the potentials, weaknesses and qualities in living environments to consequently act sustainably and make prudent/smart interventions. It is also an opportunity to encourage direct engagement with the inhabitants or the community to better understand their interests, concerns and priorities in their neighbourhoods.

\section{References}

Batty, M. (2012). Urban Regeneration as Self-Organization. Architectural Design, 215, 54-59

Berardi, U. (2013). Sustainability assessment of urban communities through rating systems. Environment, Development and Sustainability, 15(6), 1573-1591.

Bird, K. (2015). Neighbourhood Sustainability Assessment: Connecting Impact with Policy Intent. Burnaby: Simon Fraser University.

Blum, A., Grant, M. (2006). Sustainable neighbourhoods: Assessment tools for renovation and development. Journal of International Research Publications: Ecology and Safety, 1, 37-54.

Bourdic L., Salat, S., Nowacki, C. (2012). Assessing cities: a new system of cross-scale spatial indicators, Building Research \& Information, 40(5), 592-605.

Clark, H., Aranoff, M., Lavine, E., Suteethorn, K. (2013). LEED for Neighborhood Development: Does it Capture Livability? Berkeley Planning Journal, 26(1), 150-166.

Choguill, C. L. (2008). Developing Sustainable Neighborhoods. Habitat International, 32, 41-48.

Haapio, A. (2012). Towards sustainable urban communities. Environmental Impact Assessment Review, 32(1), $165-169$.

Karol, E. (2009). Tools for Measuring Progress Towards Sustainable Neighborhood Environments. Sustainability, 1, 612-627. 
Kreutz S. (2009). Urban Improvement Districts in Germany: New legal instruments for joint proprietor activities in area development. J Urban Regeneration \& Renewal, 2, 304-317.

Lin, K.W., Shih, C.M. (2016). The Comparative Analysis of Neighborhood Sustainability Assessment Tools Environment and Planning B: Planning and Design. [Online] Available: http://journals.sagepub.com/doi/abs/10.1177/0265813516667299? ssource=mfr\&rss=1 (November 2017).

Lombardi, P., Trossero, E., (2013). Beyond energy efficiency in evaluating sustainable development in planning and the built environment. International Journal of Sustainable Building Technology and Urban Development, 4(4), 274-282 2013.

Lützkendorf, T., Balouktsi, M. (2017). Assessing a Sustainable Urban Development: Typology of Indicators and Sources of Information. Procedia Environmental Sciences, 38, 546-553.

Mori, K., \& Christodoulou, A. (2012). Review of Sustainability Indices and Indicators: Towards a New City Sustainability Index (CSI). Environmental Impact Assessment Review, 32, 94-106.

Säynäjoki, E., Kyrö, R., Heinonen, J., Junnila, S. (2012). An assessment of the applicability of three international neighbourhood sustainability rating systems to diverse local conditions, with a focus on Nordic case areas. Int. J. Sustain. Build. Technol. Urban Dev. 2012, 3, 96-104.

Sharifi A, Murayama A. (2015). Viability of using global standards for neighbourhood sustainability assessment: Insights from a comparative case study. J Environ Plan Manage, 58, 1-23.

Sharifi, A., \& Murayama, A. (2013). A critical review of seven selected neighborhood sustainability assessment tools. Environmental Impact Assessment Review, 38, 73-87.

Sullivan, L. Rydin, Y. (2015). Neighbourhood Sustainability Frameworks - A Literature Review. London: Centre for Urban Sustainability and Resilience College London.

Waldron, D. and Miller, D. (2013). Regenerative Sustainability at the Neighborhood Scale. US: University of British Columbia.

Zheng, H.W., Shen G, Yan Song, Sun B., Hong J. (2016). Neighborhood sustainability in urban renewal: An assessment framework. Environment and Planning B, 44(5), $903-924$. 